Ю.В. Кириченко ${ }^{1}$ Ю.Ф. Лонін ${ }^{1}$, О.В. Струцінський ${ }^{2}$, О.Л. Кузнєцов ${ }^{3}$ О.В. Бєсова ${ }^{3}$, О.В. Лукашук ${ }^{3}$

${ }^{1}$ Національний науковий иеентр Харківського фізико-технічного інституту, Харків

${ }^{2}$ Командування Повітряних Сил Збройних Сил України, Вінниия

${ }^{3}$ Харківський наџіональний університет Повітряних Сил ім. І. Кожедуба, Харків

\title{
ПЛАНАРНІ АНТЕНИ \\ НА ОСНОВІ ПОЗДОВЖНІХ НЕОДНОРІДНИХ ПЛАЗМОВИХ ШАРІВ
}

Ефективним засобом зниження радіолокаиійної помітності антен літальних апаратів є застосування плазмових антен. Для них ефективна поверхня розсіяння електромагнітних хвиль менша на декілька порядків, ніж для металевих антен. В роботі досліджено дві моделі планерної плазмової антени. В першій моделі покритий діелектриком поздовжньо неоднорідний шар плазми знаходиться на металевій поверхні. У другій моделі такий же шар плазми знаходиться між двома діелектриками. В обох випадках плазма є електронною, холодною та ізотропною. Поздовжня неоднорідність враховується методом спектрального розкладання електромагнітного поля по набору поверхневих та просторових хвиль. Обчислено нормовані діаграми спрямованості (НДС) та коефіцієнти перетворення енергї поверхневих хвиль у енергію випромінювання. Показано, що НДС мають одну пелюстку, максимум якої знаходиться під гострим кутом до площини антени. Ширина пелюстки складає декілька градусів.

Ключові слова: плазмові антени, неоднорідна плазма, метод спектрального розкладання, діаграма спрямованості випромінювання, відкриті хвилеводи.

\section{Вступ}

Постановка задачі. В даний час найбільш гострими проблемами у розвитку та створенні нових зразків військової техніки $є$ зниження помітності військових об'єктів у різних діапазонах хвиль, а також вдосконалення захисту об'єктів у радіоелектронній боротьбі. Зниження помітності має здійснюватися у радіо, інфрачервоному, видимому та акустичному діапазонах хвиль. При цьому найбільш важливим є завдання зниження помітності у радіодіапазоні. Пов'язано це з тим, що радіолокаційні засоби забезпечують найбільшу дальність виявлення.

При зниженні радіолокаційної помітності найбільш важливими елементами є: антени літальних апаратів, антени радіолокаторів, антени радіоелектронної протидії і т.д. Насамперед виникає проблема зниження ефективної поверхні розсіяння електромагнітних хвиль антенами без значного погіршення їх характеристик.

Головними критеріями при зниженні радіолокаційної помітності антенних комплексів $\epsilon$ :

- маскування антенних комплексів в режимі радіомовчання для максимального зниження їх помітності радіолокаторами;

- швидкість, з якою антени входять у робочий режим;

- швидкість, $з$ якою антенний комплекс переходить у режим маскування.

Сучасні струмопровідні елементи антен виготовляються 3 металу. Метали, володіючи високою провідністю добре відбивають електромагнітні хвилі у широкому діапазоні частот, в тому числі у радіодіапазоні. Це є причиною високої радіолокаційної помітності традиційних антен, що є їх недоліком. Традиційні методи маскування таких антен не можуть бути використані без погіршення їх технічних характеристик.

Перспективним шляхом створення малопомітних антен є використання низькотемпературної плазми. Крім того, плазмовими антенами можна швидко керувати, перебудовуючи робочу частоту та діаграми спрямованості. У плазмових антенах струмонесучим елементом є газовий розряд в обмеженому просторі. Антени з плазмою газорозрядних трубок мають ряд переваг з точки зору використання їх при маскуванні у радіодіапазоні:

- незначна помітність для радіолокаційних систем у режимі радіомовчання;

- швидке включення та майже безінерційна зміна параметрів випромінювання, в тому числі робочої частоти.

Аналіз останніх досліджень і публікацій. Серед експериментальних досліджень 3 фізики плазмових антен слід зазначити роботи [1-5]. Рівняння Максвелла допускають для циліндричного металевого дроту рішення у вигляді поверхневої азимутально-симетричної $E$-хвилі, яка носить назву хвилі Зоммерфельда. У плазмовому циліндричному стовпі також існують азимутально-симетричні поверхневі електромагнітні хвилі (ПЕВ). У роботі [6] вперше була продемонстрована можливість генерації про- 
тяжних плазмових стовпів поверхневою хвилею.

Автор помітив, що при іонізації газу у порожнині резонатора плазма поширюється за межі резонатора і при цьому підтримується біжучою хвилею, яку він ідентифікував як ПЕВ. За цим почалася активна розробка різних хвилеводних систем для ефективного збудження поверхневих хвиль [7]. Почалося також систематичне вивчення газових розрядів, створюваних та підтримуваних поверхневими електромагнітними хвилями, що поширюються по обмеженій плазмі. Крім циліндричних газорозрядних трубок поверхневі хвилі досліджуються також у плоских структурах [8].

Теорія поверхневих хвиль у плоскому плазмовому шарі, що знаходиться у вільному просторі, викладена в [9]. Теорія ПЕВ не дає обмеження для густини плазми будь-яким максимальним значенням, проте існують практичні обмеження густини, пов'язані $з$ величиною потужності джерел радіохвиль, яка може бути розсіяна в плазмі без пошкодження діелектричної оболонки розрядної системи. Густина плазми, що генерується ПЕВ при атмосферному тиску, може досягати значень порядку $10^{15} \mathrm{~cm}^{-3}$.

Згасання поверхневих електромагнітних хвиль в обмеженій плазмі у напрямку поширення відносно мало. Пов'язано це $з$ тим, що значна частина потоку енергії поверхневих хвиль зосереджена поза провідником. Газорозрядна плазма має властивість швидкого включення на стадії іонізації та виключення в процесі рекомбінації. Це дозволяє створювати електронно-керовані антени, здатні швидко вмикатися та короткочасно працювати в активному режимі. Велику частину часу така антена може перебувати у пасивному стані, тобто не бути видимою для радіовиявлення.

Діаграми спрямованості плазмових антен поверхневих хвиль, що біжать, мають наступні властивості [10] :

- добре виражений максимум під малими кутами до осі направляючої структури;

- мала ширина на напіввисоті;

- незначний рівень бічних пелюсток.

Всі ці властивості плазмових антен поверхневих хвиль дозволяють сподіватися на успішне застосування їх в техніці літальних апаратів.

Антени 3 поздовжньо однорідної плазмою $є$ ідеалізацією. Практично завжди у реальних експериментах є гладкі неперервні поздовжні неоднорідності. Тому для правильного розуміння процесу випромінювання у циліндричних плазмових антенах та їх конструювання необхідно досліджувати, наскільки коефіцієнти трансформації енергії поверхневої хвилі у випромінюванні залежать від ступеня неоднорідності щільності плазми.

Врахування цієї неоднорідності має принципо- ве значення, так як вона впливає на ефективність роботи будь-якої плазмової антени біжучої хвилі в тому числі планарної і циліндричної. Опис відкритих систем, що проводять хвилі пов'язано з певними труднощами, які викликані необхідністю врахування просторових (хвиль безперервного спектра).

Мета статті - метою статті $є$ дослідження перетворення поверхневих хвиль у випромінювання у плоскому обмеженому шарі плазми кінцевої товщини із густиною, яка швидко змінюється в поздовжньому напрямку.

Плазма знаходиться між плоскою металевою підкладкою, повітряним зазором та діелектриком (Розділ 2) або між двома шарами діелектрика (Розділ 3).

Основи методу, що дозволяє досліджувати подібні системи, описані у Розділі 1.

\section{Виклад основного матеріалу}

\section{Розділ 1. Метод спектрального розкладання для планарного відкритого хвилеводу}

Під планарним відкритим плазмовим хвилеводом ми розуміємо плоский шар плазми, обмежений з одного або двох сторін діелектриком. Відомо, що у такій системі поверхнева хвиля простягається за межі обмежуючих діелектриків.

Згідно з методом спектрального розкладання, викладеного В.В. Шевченко у монографії [11], повне поле відкритого хвилеводу представляється у вигляді розкладання по повному набору хвиль, що складається $з$ поверхневої та просторової хвилі. Коефіцієнти цього розкладання при наявності неоднорідності є функціями поздовжньої координати. Вони задовольняють деякій системі інтегродиференціальних рівнянь. Цю систему рівнянь у разі повільної зміни неоднорідності можна розв'язати аналітично методом послідовних наближень. Але у важливому випадку швидкої зміни поздовжньої неоднорідності, коли випромінювання найбільш інтенсивно, система інтегро-диференціальних рівнянь може бути розв'язана тільки чисельно. Зручність методу спектрального розкладання полягає в тому, що коефіцієнти розкладання безпосередньо пов'язані з коефіцієнтами трансформації енергії поверхневої хвилі в енергію хвилі випромінювання.

Кожна з просторових хвиль окремо не має фізичного сенсу, так як повільно спадає, або зовсім не спадає до нескінченності і тому переносить нескінченно велику енергію. Проте суперпозиція цих хвиль правильно описує випромінювання електромагнітних хвиль, що виникає завдяки наявності неоднорідності відкритої структури, що випромінює. Метод спектрального розкладання може бути основою для теорії антен біжучої поверхневої хвилі.

Розглянемо планарну плазменно-діелектричну 
структуру, необмежену уздовж $x, z$. У статті розглядаються два приклади таких структур, зображених на рис. 3; 9 (Розділи 2,3).

Спочатку розглянемо шар з однорідною густиною. Плазма передбачається електронною, холодною, ізотропною та безсутичковою.

Iї діелектрична проникність дорівнює $\varepsilon(\omega)=1-\frac{\omega_{p}^{2}}{\omega^{2}}$, де $\omega-$ частота, $\omega_{p}^{2}=4 \pi n_{e} e^{2} / m_{e}-$ плазмова частота електронної плазми $\left(e, m_{e}, n_{e}-\right.$ заряд, маса та густина електронів відповідно).

Часова залежність компонент поля береться у вигляді $\exp (-i \omega t)$.

У таких планарних хвилеводах існує повільна поверхнева $E$ хвиля, що має компоненти:

$$
\begin{gathered}
E_{z 0}(y, z)=E_{z 0}(y) \exp \left( \pm i k_{z}^{0} z\right) ; \\
E_{y 0}(y, z)=E_{y 0}(y) \exp \left( \pm i k_{z}^{0} z\right) ; \\
H_{x 0}(y, z)=\Psi_{0}(y) \exp \left( \pm i k_{z}^{0} z\right) ; \Psi_{0}(y) \equiv H_{x 0}(y),
\end{gathered}
$$

де $k_{z}^{0}>k^{2}-$ хвильовий вектор поверхневої хвилі. У виразах (1) - (3) знак “+” відповідає за поширення хвилі вздовж осі z, а “-” у зворотному напрямку. Залежність компонент $E_{y 0}, E_{z 0}, \Psi_{0}$ від координати $y$ визначається граничними умовами. 3 рівнянь Максвелла випливає умова нормування, має вигляд :

$$
\int_{-\infty}^{\infty} d y \frac{1}{\varepsilon_{p}(y)}\left(\Psi_{0}(y)\right)^{2}=1 .
$$

Компоненти хвилі $E_{y 0}, E_{z 0}$ визначаються компонентою магнітного поля, або функцією $\Psi_{0}(3)$. Крім хвилі (1-3) є інші рішення рівнянь Максвелла,

$$
\begin{aligned}
& E_{z}(y, z)=E_{z}(y) \exp \left( \pm i k_{z} z\right) \\
& E_{y}(y, z)=E_{y}(y) \exp \left( \pm i k_{z} z\right) \\
& H_{x}\left(y, z, \kappa_{0}\right)=\Psi\left(y, \kappa_{0}\right) \exp \left( \pm i k_{z} z\right) ; \\
& \Psi\left(y, \kappa_{0}\right) \equiv H_{x}\left(y, \kappa_{0}\right),
\end{aligned}
$$

які існують за умови $k^{2}>k_{z}^{2}$. Це просторові швидкі хвилі. В (5) виділена залежність $\Psi\left(y, \kappa_{0}\right)$ від $\kappa_{0}$. Функція (5) не спадає на нескінченності і нормована на $\delta$ - функцію:

$$
\begin{gathered}
\int_{0}^{\infty} d y \frac{1}{\varepsilon_{p}(y)} \Psi\left(y, \kappa_{0}\right) \Psi\left(y, \tilde{\kappa}_{0}\right)=\delta\left(\kappa_{0}-\tilde{\kappa}_{0}\right), \\
\kappa_{0}^{2}=k^{2}-k_{z}^{2} .
\end{gathered}
$$

Виконується також умова ортогональності поверхневих (3) та просторових (5) хвиль

$$
\int_{0}^{\infty} d y \frac{1}{\varepsilon_{p}(y)} \Psi\left(y, \kappa_{0}\right) \Psi_{0}(y)=0 .
$$

Функції поперечного перерізу $\Psi_{0}(y)$ (4) та $\Psi\left(y, \kappa_{0}\right)$ (5) утворюють повну ортонормовану систему функцій, по якій може бути розкладена компонента повного поля $H_{x}^{t o t}(y, z)$ :

$$
\begin{gathered}
H_{x}^{\text {tot }}(y, z)=\left(B_{+}^{0} \exp \left(i k_{z}^{0} z\right)+B_{-}^{0} \exp \left(-i k_{z}^{0} z\right)\right) \Psi_{0}(y)+ \\
+\int_{0}^{\infty} d \kappa_{0}\left(B_{+}\left(\kappa_{0}\right) \exp \left(i k_{z} z\right)+B_{-}\left(\kappa_{0}\right) \exp \left(-i k_{z} z\right)\right) \Psi\left(y, \kappa_{0}\right),
\end{gathered}
$$

де перший доданок відповідає поверхневим хвилям, а другий - суперпозиції просторових хвиль.

Підставивши у $(8)$ вирази $(3 ; 5)$ для $\Psi_{0}(y)$ та $\Psi\left(y, \kappa_{0}\right)$, отримуємо вираз для компоненти повного поля $H_{x}^{\text {tot }}(y, z)$ (формули для $\Psi_{0}(y), \Psi\left(y, \kappa_{0}\right)$ конкретних систем наведені у Розділах 2-3). У (8) виділена залежність $B_{ \pm}$від $k_{z}$. Інтеграл у формулі (8) описує випромінювання.

Надалі необхідна асимптотика цього інтегралу за умови $k r=k \sqrt{y^{2}+z^{2}} \rightarrow \infty$.

Для обчислення асимптотики, згідно роботи [11], зручно перейти до комплексної змінної інтегрування $\vartheta$ :

$$
\kappa_{0}=k \sin \vartheta, \mathrm{k}_{\mathrm{z}}=\mathrm{k} \cos \vartheta
$$

При цьому показник експоненти у інтегралі, що описує випромінювання, набуває вигляду $\kappa_{0} \mathrm{y} \pm \mathrm{k}_{\mathrm{z}} \mathrm{z}= \pm \mathrm{kr} \cos (\vartheta \mp \theta)$, де $\mathrm{y}=\mathrm{r} \sin \theta, \mathrm{z}=\mathrm{r} \cos \theta$, $\theta-$ азимутальний кут.

Після цього перетворення асимптотика інтегралів в площині комплексної змінної $\vartheta$ обчислюється при $k r \rightarrow \infty$ методом перевалу.

Нехай на ділянці $0 \leq z \leq L$, як показано на рис. 3,9 , густина плазми $n_{e}(z)$ неоднорідна.

При цьому відповідно до методу спектрального розкладання [11] коефіцієнти $B_{ \pm}^{0}, B_{ \pm}$стають функціями координати $z$.

При цьому зручно зробити заміну: 


$$
\begin{aligned}
& B_{ \pm}^{0}(z)=\frac{\exp \left( \pm i\left(\gamma_{0}(z)-k_{z}^{0} z\right)\right)}{\sqrt{k_{z}^{0}}} D_{ \pm}^{0}(z) \\
& B_{ \pm}\left(\kappa_{0}, k_{z}, z\right)=\frac{1}{k_{z}} D_{ \pm}\left(\kappa_{0}, k_{z}, z\right) \text {; } \\
& \gamma_{0}(z)=\int_{0}^{z} d z k_{z}^{0}(z) \\
& \left(D_{+}^{0}\right)_{z}^{\prime}=A_{1} D_{+}^{0}+A_{2} D_{-}^{0}+\int_{0}^{\infty} d \tilde{\kappa}_{0}\left(A_{3} D_{+}\left(\tilde{\kappa}_{0}, z\right)+A_{4} D_{-}\left(\tilde{\kappa}_{0}, z\right)\right) \\
& \left(D_{-}^{0}\right)_{z}^{\prime}=\left(A_{2}\right)^{*} D_{+}^{0}+A_{1} D_{-}^{0}+\int_{0}^{\infty} d \tilde{\kappa}_{0}\left(\left(A_{4}\right)^{*} D_{+}\left(\tilde{\kappa}_{0}, z\right)+\left(A_{3}\right)^{*} D_{-}\left(\tilde{\kappa}_{0}, z\right)\right) \\
& \left(D_{+}\right)_{z}^{\prime}=A_{5} D_{+}^{0}+A_{6} D_{-}^{0}+\int_{0}^{\infty} d \tilde{\kappa}_{0}\left(A_{7} D_{+}\left(\tilde{\kappa}_{0}, z\right)+A_{8} D_{-}\left(\tilde{\kappa}_{0}, z\right)\right) \\
& \left(D_{-}\right)_{z}^{\prime}=\left(A_{6}\right)^{*} D_{+}^{0}+\left(A_{5}\right)^{*} D_{-}^{0}+\int_{0}^{\infty} d \tilde{\kappa}_{0}\left(\left(A_{8}\right)^{*} D_{+}\left(\tilde{\kappa}_{0}, z\right)+\left(A_{7}\right)^{*} D_{-}\left(\tilde{\kappa}_{0}, z\right)\right),
\end{aligned}
$$

де $A_{1}=-J_{0}(z), A_{2}=\frac{\left(k_{z}^{0}\right)_{z}^{\prime}}{2 k_{z}^{0}} \exp \left(-2 i \gamma_{0}\right)$

$$
\begin{gathered}
A_{3}=-\frac{k_{z}^{0}+\tilde{k}_{z}}{2 \sqrt{k_{z}^{0}} \tilde{k}_{z}} J_{1}\left(\tilde{\kappa}_{0}, z\right) \exp \left(i\left(\tilde{k}_{z} z-\gamma_{0}\right)\right), \\
A_{4}=-\frac{k_{z}^{0}-\tilde{k}_{z}}{2 \sqrt{k_{z}^{0}} \tilde{k}_{z}} J_{1}\left(\tilde{\kappa}_{0}, z\right) \exp \left(-i\left(\tilde{k}_{z} z+\gamma_{0}\right)\right), \\
A_{5}=-\frac{k_{z}+k_{z}^{0}}{2 \sqrt{k_{z}^{0}}} J_{2}\left(\kappa_{0}, z\right) \exp \left(i\left(\gamma_{0}-k_{z} z\right)\right), \\
A_{6}=-\frac{k_{z}-k_{z}^{0}}{2 \sqrt{k_{z}^{0}}} J_{2}\left(\kappa_{0}, z\right) \exp \left(-i\left(\gamma_{0}+k_{z} z\right)\right), \\
A_{7}=-\frac{k_{z}+\tilde{k}_{z}}{2 \tilde{k}_{z}} J_{3}\left(\kappa_{0}, \tilde{\kappa}_{0}, z\right) \exp \left(i\left(\tilde{k}_{z}-k_{z}\right) z\right), \\
A_{8}=-\frac{k_{z}-\tilde{k}_{z}}{2 \tilde{k}_{z}} J_{3}\left(\kappa_{0}, \tilde{\kappa}_{0}, z\right) \exp \left(-i\left(\tilde{k}_{z}+k_{z}\right) z\right), \\
J_{3}\left(\kappa_{0}, \tilde{\kappa}_{0}, z\right)= \\
J_{0}(z)=\int_{0}^{\infty} d y \frac{1}{\varepsilon_{p}(y)} H_{x 0}(y)\left(H_{x 0}(y)\right)_{z}^{\prime}, \\
J_{1}\left(\tilde{\kappa}_{0}, z\right)=\int_{0}^{\infty} d y \frac{1}{\varepsilon_{p}(y)} H_{x 0}(y)\left(H_{x}\left(y, \tilde{\kappa}_{0}\right)\right)_{z}^{\prime},(15) \\
\int_{p}(y)
\end{gathered}
$$

інтеграли $J_{0}, J_{1}, J_{2}, J_{3}$ залежать від $z$, оскільки від цієї координати залежать корінь дисперсійного рівняння $k_{z}^{0}(z)$ та плазмова частота $\omega_{p}(z)$. Рівняння (11) - (14) повинні бути доповнені наступними граничними умовами :

$$
\begin{aligned}
& D_{+}^{0}(z=0)=1 ; D_{+}(z=0)=0 ; \\
& D_{-}^{0}(z=L)=0 ; D_{-}(z=L),
\end{aligned}
$$

які відповідають хвилі, що набігає з області $z=-\infty$ на ділянку неоднорідності плазми. Коефіцієнти $A_{i}$, що входять до рівняння (11) - (14) мають сенс коефіцієнтів зв'язку прямих поверхневих, зворотних поверхневих та хвиль випромінювання між собою. Цей зв'язок виникає завдяки поздовжній неоднорідності щільності плазми. Відзначимо, що за відсутності неоднорідності, коли $k_{z}^{0}$ i $\omega_{P}$ не залежить від $z$, інтеграли $J_{0}, J_{1}, J_{2}, J_{3}$, а відповідно і $A_{i}(i=1 \ldots 8)$ дорівнюють нулю. При цьому, як видно 3 рівнянь (11) - (14), граничних умов (17) і формул (15) - (16) випромінювання відсутне. Комплексні амплітуди $D_{ \pm}^{0}(z), D_{ \pm}\left(\kappa_{0}, z\right)$ і коефіцієнти $A_{i}$ зручно розкласти на дійсні та уявні частини наступним чином:

$D_{+}^{0}(z)=f_{1}(z)+i g_{1}(z), D_{-}^{0}(z)=f_{2}(z)+i g_{2}(z)$,

$D_{+}\left(\kappa_{0}, z\right)=f_{3}\left(\kappa_{0}, z\right)+i g_{3}\left(\kappa_{0} z\right)$,

$D_{-}\left(\kappa_{0}, z\right)=f_{4}\left(\kappa_{0}, z\right)+i g_{4}\left(\kappa_{0} z\right), A_{1}(z)=a_{1}(z)$,

$a_{1}(z)=-J_{0}(z), A_{2}(z)=a_{2}(z)-i b_{2}(z)$,

$a_{2}(z)=S_{0}(z) \cos \left(2 \gamma_{0}(z)\right), b_{2}(z)=S_{0}(z) \sin \left(2 \gamma_{0}(z)\right)$,

$S_{0}(z)=\frac{\left(k_{z}^{0}\right)_{z}^{\prime}}{2 k_{z}^{0}}, A_{3}\left(\tilde{\kappa}_{0}, z\right)=a_{3}\left(\tilde{\kappa}_{0}, z\right)-i b_{3}\left(\tilde{\kappa}_{0}, z\right)$, 


$$
\begin{aligned}
& a_{3}\left(\tilde{\kappa}_{0}, z\right)=-\frac{k_{z}^{0}+\tilde{k}_{z}}{2 \sqrt{k_{z}^{0}} \tilde{k}_{z}} J_{1}\left(\tilde{\kappa}_{0}, z\right) \cos \left(\gamma_{0}-\tilde{k}_{z} z\right) \\
& b_{3}\left(\tilde{\kappa}_{0}, z\right)=-\frac{k_{z}^{0}+\tilde{k}_{z}}{2 \sqrt{k_{z}^{0}} \tilde{k}_{z}} J_{1}\left(\tilde{\kappa}_{0}, z\right) \sin \left(\gamma_{0}-\tilde{k}_{z} z\right), \\
& A_{4}\left(\tilde{\kappa}_{0}, z\right)=a_{4}\left(\tilde{\kappa}_{0}, z\right)-i b_{4}\left(\tilde{\kappa}_{0}, z\right) \text {, } \\
& a_{4}\left(\tilde{\kappa}_{0}, z\right)=-\frac{k_{z}^{0}-\tilde{k}_{z}}{2 \sqrt{k_{z}^{0}} \tilde{k}_{z}} J_{1}\left(\tilde{\kappa}_{0}, z\right) \cos \left(\gamma_{0}+\tilde{k}_{z} z\right), \\
& b_{4}\left(\tilde{\kappa}_{0}, z\right)=-\frac{k_{z}^{0}-\tilde{k}_{z}}{2 \sqrt{k_{z}^{0}} \tilde{k}_{z}} J_{1}\left(\tilde{\kappa}_{0}, z\right) \sin \left(\gamma_{0}+\tilde{k}_{z} z\right) \text {, } \\
& A_{5}\left(\kappa_{0}, z\right)=a_{5}\left(\kappa_{0}, z\right)+i b_{5}\left(\kappa_{0}, z\right) \text {, } \\
& a_{5}\left(\kappa_{0} z\right)=-\frac{k_{z}+k_{z}^{0}}{2 \sqrt{k_{z}^{0}}} J_{2}\left(\kappa_{0}, z\right) \cos \left(\gamma_{0}-k_{z} z\right) \text {, } \\
& b_{5}\left(\kappa_{0} z\right)=-\frac{k_{z}+k_{z}^{0}}{2 \sqrt{k_{z}^{0}}} J_{2}\left(\kappa_{0}, z\right) \sin \left(\gamma_{0}-k_{z} z\right), \\
& A_{6}\left(\kappa_{0}, z\right)=a_{6}\left(\kappa_{0}, z\right)-i b_{6}\left(\kappa_{0}, z\right) \text {, } \\
& a_{6}\left(\kappa_{0}, z\right)=-\frac{k_{z}-k_{z}^{0}}{2 \sqrt{k_{z}^{0}}} J_{2}\left(\kappa_{0}, z\right) \cos \left(\gamma_{0}+k_{z} z\right) \text {, } \\
& b_{6}\left(\kappa_{0}, z\right)=-\frac{k_{z}-k_{z}^{0}}{2 \sqrt{k_{z}^{0}}} J_{2}\left(\kappa_{0}, z\right) \sin \left(\gamma_{0}+k_{z} z\right) \text {, } \\
& A_{7}\left(\tilde{\kappa}_{0}, \kappa_{0}, z\right)=a_{7}\left(\tilde{\kappa}_{0}, \kappa_{0}, z\right)+i b_{7}\left(\tilde{\kappa}_{0}, \kappa_{0}, z\right) \text {, } \\
& a_{7}\left(\tilde{\kappa}_{0}, \kappa_{0}, z\right)=-\frac{k_{z}+\tilde{k}_{z}}{2 \tilde{k}_{z}} J_{3}\left(\tilde{\kappa}_{0}, \kappa_{0}, z\right) \cos \left(\left(\tilde{k}_{z}-k_{z}\right) z\right) \text {, } \\
& b_{7}\left(\tilde{\kappa}_{0}, \kappa_{0}, z\right)=-\frac{k_{z}+\tilde{k}_{z}}{2 \tilde{k}_{z}} J_{3}\left(\tilde{\kappa}_{0}, \kappa_{0}, z\right) \sin \left(\left(\tilde{k}_{z}-k_{z}\right) z\right), \\
& A_{8}\left(\tilde{\kappa}_{0}, \kappa_{0}, z\right)=a_{8}\left(\tilde{\kappa}_{0}, \kappa_{0}, z\right)-i b_{8}\left(\tilde{\kappa}_{0}, \kappa_{0}, z\right), \\
& a_{8}\left(\tilde{\kappa}_{0}, \kappa_{0}, z\right)=-\frac{k_{z}-\tilde{k}_{z}}{2 \tilde{k}_{z}} J_{3}\left(\tilde{\kappa}_{0}, \kappa_{0}, z\right) \cos \left(\left(\tilde{k}_{z}+k_{z}\right) z\right) \text {, } \\
& b_{8}\left(\tilde{\kappa}_{0}, \kappa_{0}, z\right)=-\frac{k_{z}-\tilde{k}_{z}}{2 \tilde{k}_{z}} J_{3}\left(\tilde{\kappa}_{0}, \kappa_{0}, z\right) \sin \left(\left(\tilde{k}_{z}+k_{z}\right) z\right) \text {, }
\end{aligned}
$$$$
f_{1}(z)=1+\int_{0}^{z} d z\left\{\alpha_{1}(z) f_{1}(z)+\alpha_{2}(z) f_{2}(z)+\beta_{2}(z) g_{2}(z)\right\}+
$$$$
+\int_{0}^{z} d z \int_{C} d \tilde{\vartheta}\left\{\alpha_{3}(\tilde{\vartheta}, z) f_{3}(\tilde{\vartheta}, z)+\beta_{3}(\tilde{\vartheta}, z) g_{3}(\tilde{\vartheta}, z)+\alpha_{4}(\tilde{\vartheta}, z) f_{4}(\tilde{\vartheta}, z)+\beta_{4}(\tilde{\vartheta}, z) g_{4}(\tilde{\vartheta}, z)\right\}
$$$$
g_{1}(z)=\int_{0}^{z} d z\left\{\alpha_{1}(z) g_{1}(z)+\alpha_{2}(z) g_{2}(z)-\beta_{2}(z) f_{2}(z)\right\}+
$$$$
+\int_{0}^{z} d z \int_{C} d \tilde{\vartheta}\left\{\alpha_{3}(\tilde{\vartheta}, z) g_{3}(\tilde{\vartheta}, z)-\beta_{3}(\tilde{\vartheta}, z) f_{3}(\tilde{\vartheta}, z)+\alpha_{4}(\tilde{\vartheta}, z) g_{4}(\tilde{\vartheta}, z)-\beta_{4}(\tilde{\vartheta}, z) f_{4}(\tilde{\vartheta}, z)\right\}
$$ 


$$
\begin{aligned}
& f_{2}(z)=\int_{L}^{z} d z\left\{\alpha_{2}(z) f_{1}(z)-\beta_{2}(z) g_{1}(z)+\alpha_{1}(z) g_{2}(z)\right\}+ \\
& +\int_{L}^{z} d z \int_{C} d \tilde{\vartheta}\left\{\alpha_{4}(\tilde{\vartheta}, z) f_{3}(\tilde{\vartheta}, z)-\beta_{4}(\tilde{\vartheta}, z) g_{3}(\tilde{\vartheta}, z)+\alpha_{3}(\tilde{\vartheta}, z) f_{4}(\tilde{\vartheta}, z)-\beta_{3}(\tilde{\vartheta}, z) g_{4}(\tilde{\vartheta}, z)\right\} \\
& g_{2}(z)=\int_{L}^{z} d z\left\{\alpha_{2}(z) g_{1}(z)+\beta_{2}(z) f_{1}(z)+\alpha_{1}(z) f_{2}(z)\right\}+ \\
& +\int_{L}^{z} d z \int_{C} d \tilde{\vartheta}\left\{\alpha_{4}(\tilde{\vartheta}, z) g_{3}(\tilde{\vartheta}, z)+\beta_{4}(\tilde{\vartheta}, z) f_{3}(\tilde{\vartheta}, z)+\alpha_{3}(\tilde{\vartheta}, z) g_{4}(\tilde{\vartheta}, z)+\beta_{3}(\tilde{\vartheta}, z) f_{4}(\tilde{\vartheta}, z)\right\} \text {; } \\
& f_{3}(\vartheta, z)=\int_{0}^{z} d z\left\{\alpha_{5}(\vartheta, z) f_{1}(z)-\beta_{5}(\vartheta, z) g_{1}(z)+\alpha_{6}(\vartheta, z) f_{2}(z)+\beta_{6}(\vartheta, z) g_{2}(z)\right\}+ \\
& +\int_{0}^{z} d z \int_{C} d \tilde{\vartheta}\left\{\alpha_{7}(\tilde{\vartheta}, \vartheta, z) f_{3}(\tilde{\vartheta}, z)-\beta_{7}(\tilde{\vartheta}, \vartheta, z) g_{3}(\tilde{\vartheta}, z)+\alpha_{8}(\tilde{\vartheta}, \vartheta, z) f_{4}(\tilde{\vartheta}, z)+\beta_{8}(\tilde{\vartheta}, \vartheta, z) g_{4}(\tilde{\vartheta}, z)\right\} ; \\
& g_{3}(\vartheta, z)=\int_{0}^{z} d z\left\{\beta_{5}(\vartheta, z) f_{1}(z)+\alpha_{5}(\vartheta, z) g_{1}(z)+\alpha_{6}(\vartheta, z) g_{2}(z)-\beta_{6}(\vartheta, z) f_{2}(z)\right\}+ \\
& +\int_{0}^{z} d z \int_{C} d \tilde{\vartheta}\left\{\alpha_{7}(\tilde{\vartheta}, \vartheta, z) g_{3}(\tilde{\vartheta}, z)+\beta_{7}(\tilde{\vartheta}, \vartheta, z) f_{3}(\tilde{\vartheta}, z)+\alpha_{8}(\tilde{\vartheta}, \vartheta, z) g_{4}(\tilde{\vartheta}, z)-\beta_{8}(\tilde{\vartheta}, \vartheta, z) f_{4}(\tilde{\vartheta}, z)\right\} ; \\
& f_{4}(\vartheta, z)=\int_{L}^{z} d z\left\{\alpha_{6}(\vartheta, z) f_{1}(z)-\beta_{6}(\vartheta, z) g_{1}(z)+\alpha_{5}(\vartheta, z) f_{2}(z)+\beta_{5}(\vartheta, z) g_{2}(z)\right\}+ \\
& +\int_{L}^{z} d z \int_{C} d \tilde{\vartheta}\left\{\alpha_{8}(\tilde{\vartheta}, \vartheta, z) f_{3}(\tilde{\vartheta}, z)-\beta_{8}(\tilde{\vartheta}, \vartheta, z) g_{3}(\tilde{\vartheta}, z)+\alpha_{7}(\tilde{\vartheta}, \vartheta, z) f_{4}(\tilde{\vartheta}, z)+\beta_{7}(\tilde{\vartheta}, \vartheta, z) g_{4}(\tilde{\vartheta}, z)\right\} \\
& g_{4}(\vartheta, z)=\int_{L}^{z} d z\left\{\alpha_{6}(\vartheta, z) g_{1}(z)+\beta_{6}(\vartheta, z) f_{1}(z)+\alpha_{5}(\vartheta, z) g_{2}(z)-\beta_{5}(\vartheta, z) f_{2}(z)\right\}+ \\
& +\int_{L}^{z} d z \int_{C} d \tilde{\vartheta}\left\{\alpha_{8}(\tilde{\vartheta}, \vartheta, z) g_{3}(\tilde{\vartheta}, z)+\beta_{8}(\tilde{\vartheta}, \vartheta, z) f_{3}(\tilde{\vartheta}, z)+\alpha_{7}(\tilde{\vartheta}, \vartheta, z) g_{4}(\tilde{\vartheta}, z)-\beta_{7}(\tilde{\vartheta}, \vartheta, z) f_{4}(\tilde{\vartheta}, z)\right\},
\end{aligned}
$$

де коефіцієнти $\alpha_{i}, \beta_{i}(i=1 \ldots 8)$ визначаються наступними формулами:

$$
\begin{gathered}
\alpha_{1}(z)=a_{1}(z), \alpha_{2}(z)=a_{2}(z), \beta_{2}(z)=b_{2}(z), \\
\alpha_{3}(\tilde{\vartheta}, z)=\tilde{k}_{z} a_{3}\left(\tilde{\kappa}_{0}, z\right), \beta_{3}\left(\tilde{\vartheta}_{,}, z\right)=\tilde{k}_{z} b_{3}\left(\tilde{\kappa}_{0}, z\right), \\
\alpha_{4}(\tilde{\vartheta}, z)=\tilde{k}_{z} a_{4}\left(\tilde{\kappa}_{0}, z\right), \beta_{4}(\tilde{\vartheta}, z)=\tilde{k}_{z} b_{4}\left(\tilde{\kappa}_{0}, z\right), \\
\alpha_{5}(\theta, z)=a_{5}\left(\kappa_{0}, z\right), \beta_{5}(\vartheta, z)=b_{5}\left(\kappa_{0}, z\right), \\
\alpha_{6}(\vartheta, z)=a_{6}\left(\kappa_{0}, z\right), \beta_{6}(\vartheta, z)=b_{6}\left(\kappa_{0}, z\right), \\
\alpha_{7}(\tilde{\vartheta}, \vartheta, z)=\tilde{k}_{z} a_{7}\left(\tilde{\kappa}_{0}, \kappa_{0}, z\right), \\
\beta_{7}(\tilde{\vartheta}, \vartheta, z)=\tilde{k}_{z} b_{7}\left(\tilde{\kappa}_{0}, \kappa_{0}, z\right), \\
\alpha_{8}(\tilde{\vartheta}, \vartheta, z)=\tilde{k}_{z} a_{8}\left(\tilde{\kappa}_{0}, \kappa_{0}, z\right), \\
\beta_{8}(\tilde{\vartheta}, \vartheta, z)=\tilde{k}_{z} b_{8}\left(\tilde{\kappa}_{0}, \kappa_{0}, z\right)
\end{gathered}
$$

Використовуючи асімптотику інтеграла з виразу (8), де $B_{ \pm}$залежать від координати z, i, обчислюючи відповідний вектор Пойнтінга, знаходимо кутовий розподіл потужності випромінювання під гострими кутами $P^{+}(\theta)$ і тупими кутами $P^{-}(\theta)$ :

$$
\begin{gathered}
\frac{d P^{+}(\theta)}{d \theta}=\frac{c}{8 \pi k}\left(f_{3}^{2}(\theta, L)+g_{3}^{2}(\theta, L)\right) ; \\
\frac{d P^{-}(\theta)}{d \theta}=\frac{c}{8 \pi k}\left(f_{4}^{2}(\pi-\theta, 0)+g_{4}^{2}(\pi-\theta, 0)\right) .
\end{gathered}
$$

Амплітуди $f_{1}(z), g_{1}(z), f_{2}(z), g_{2}(z)$ визначають поле поверхневої хвилі та відповідний вектор Пойнтінга, що дозволяє знайти потужності $P_{0}^{+}(z)$ i $P_{0}^{-}(z)$ поверхневої хвилі, що пройшла та відбилася, відповідно. Коефіцієнти проходження $\eta_{0}^{+}$і відбиття $\eta_{0}^{-}$поверхневої хвилі визначаються співвідношеннями:

$$
\begin{aligned}
& \eta_{0}^{+}=\frac{P_{0}^{+}(z \rightarrow \infty)}{P_{0}^{+}(z \rightarrow-\infty)}=\left(f_{1}^{2}(L)+g_{1}^{2}(L)\right) ; \\
& \eta_{0}^{-}=\frac{P_{0}^{-}(z \rightarrow \infty)}{P_{0}^{+}(z \rightarrow-\infty)}=\left(f_{2}^{2}(0)+g_{2}^{2}(0)\right) .
\end{aligned}
$$

Формули (26) дають діаграми спрямованості випромінювання, а також коефіцієнти $\eta^{+}$i $\eta^{-}$пе- 
ретворення енергії поверхневої хвилі в енергію випромінювання під гострими і тупими кутами $\theta$ відповідно:

$$
\begin{gathered}
\eta^{+}=\frac{1}{P_{0}^{+}(z \rightarrow-\infty)} \int_{0}^{\pi / 2} d \theta \frac{d P^{+}(\theta)}{d \theta}=\int_{0}^{\pi / 2} d \theta\left(f_{3}^{2}(\theta, L)+g_{3}^{2}(\theta, L)\right) ; \\
\eta^{-}=\frac{1}{P_{0}^{+}(z \rightarrow-\infty)} \int_{\pi}^{\pi / 2} d \theta \frac{d P^{-}(\theta)}{d \theta}= \\
=\int_{\pi}^{\pi / 2} d \theta\left(f_{4}^{2}(\pi-\theta, 0)+g_{4}^{2}(\pi-\theta, 0)\right) .
\end{gathered}
$$

Розв'язання системи інтегральних рівнянь (18$25)$ в загальному вигляді є досить складною обчислювальною задачею. Основні труднощі пов'язані 3 обчисленням контурного інтеграла $\int_{C} d \tilde{\vartheta}\{\}$.

В роботі [10] показано, що в деяких важливих випадках можна обмежитися інтегруванням по частині контуру $C_{1}$ (рис. 1), тобто у рівняннях (18-25) зробити наступну заміну:

$$
\int_{C} d \tilde{\vartheta}\{\} \rightarrow \int_{0}^{\pi / 2} d \tilde{\vartheta}\{\} .
$$

У рівняннях (11-14) це відповідає заміні

$$
\int_{0}^{\infty} d \tilde{\kappa}_{0}\{\} \rightarrow \int_{0}^{k} d \tilde{\kappa}_{0}\{\} .
$$

Можливість такої заміни пов'язана насамперед 3 тим, що точки перевалу, що визначають випромінювання, знаходяться саме на інтервалі $\mathrm{C}_{1}$, тобто при $0 \leq \operatorname{Re} \vartheta \leq \pi / 2, \operatorname{Im} \vartheta=0$. У статті [12] методом спектрального розкладання чисельно досліджено поширення поверхневої хвилі вздовж відкритої системи із змінним імпедансом. У цій роботі не враховувалися відбиті поверхневі хвилі, а також хвилі випромінювання під кутами $\theta>\pi / 2$. Замість (37) використовувалася заміна

$$
\int_{C} d \tilde{\vartheta}\{\} \rightarrow \int_{0}^{\theta_{\max }} d \theta\{\},
$$

та припускалось, що кут, під яким розташована головна пелюстка випромінювання, знаходиться в інтервалі $0 \leq \theta \leq \theta_{\max }$, де $\theta_{\max } \leq \pi / 8$. Автори роботи [12] відзначали, проте, що для поліпшення точності обчислень слід збільшувати величину $\theta_{\max } \cdot \mathrm{У}$ нашій роботі $\theta_{\max }=\pi / 2$.

Після заміни (28) система рівнянь (18-25) розв'язувалась методом послідовних наближень. В якості нульового наближення були взяті наступні значення амплітуд:

$$
\begin{gathered}
f_{1}(z)=1, g_{1}(z)=f_{2}(z)=g_{2}(z)=f_{3}(\vartheta, z)= \\
=g_{3}(\vartheta, z)=f_{4}(\vartheta, z)=g_{4}(\vartheta, z)=0 .
\end{gathered}
$$

Співвідношення (29) відповідає проходженню пове- рхневої хвилі через ділянку неоднорідної плазми без спотворення. Підставляючи (29) в праві частини рівнянь (18-25), отримуємо перше наближення для амплітуд, потім використовуємо отримані амплітуди у правих частинах (18-25), тощо. Відзначимо, що ітераційний процес досить швидко сходиться.

Для чисельного аналізу слід перейти до безрозмірної координатної $\tilde{z}=z / L$. Будемо вважати, що густина плазми $n_{e}(\tilde{z})$ при $0 \leq \tilde{z} \leq 1$ спадає таким чином, що діелектрична проникність $\varepsilon_{p}(\tilde{z})=1-\omega_{p}^{2}(\tilde{z}) / \omega^{2}$ росте лінійно, як показано на рис. 2.

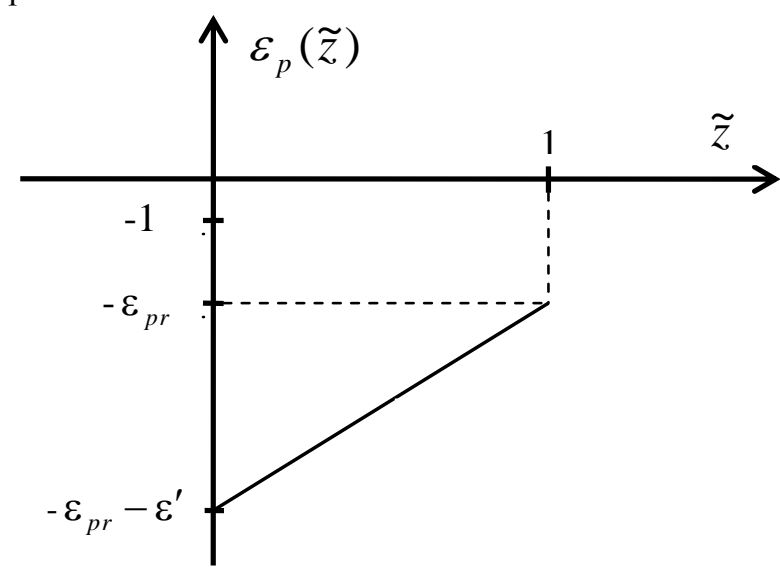

Рис. 2. Залежність діелектричної проникності плазми $\varepsilon_{p}(\tilde{z})$ від $\tilde{z}=z / L$ на ділянці

3 поздовжньою неоднорідністю густини плазми (суцільна лінія).

Джерело: розроблено авторами.

Залежність $\varepsilon_{p}(\tilde{z})$ наступна:

$$
\begin{gathered}
\varepsilon_{p}(\tilde{z})=-\varepsilon_{p r}-\varepsilon^{\prime}+\varepsilon^{\prime} \tilde{z}, \\
-\varepsilon_{p r}-\varepsilon^{\prime} \leq \varepsilon_{p}(\tilde{z}) \leq-\varepsilon_{p r}, n p u 0 \leq \tilde{z} \leq 1,
\end{gathered}
$$

де $\tilde{z}=z / L, \varepsilon_{p r}>0$ і $\varepsilon^{\prime}>0$ - параметри. Параметр $\varepsilon$ ' дорівнює градієнту діелектричної проникності плазми $\varepsilon^{\prime}=\left(\varepsilon_{p}\right)_{\tilde{z}}^{\prime}$.

Довжина поверхневої хвилі з наближенням до правого краю ділянки неоднорідності зменшується,

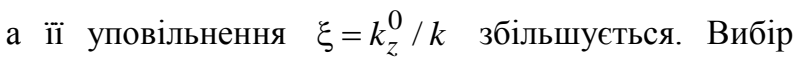
$\varepsilon_{p}(\tilde{z})$ у вигляді лінійної функції не $\epsilon$ принциповим, тому що нас цікавлять лише загальні закономірності залежності характеристик випромінювання від середньої швидкості зміни $\varepsilon_{p}(\tilde{z})$ в межах ділянки неоднорідності. Підкреслимо, що функція $\varepsilon_{p}(\tilde{z})$ може бути довільною. Із рис. 2 та формули (30) видно, що величина $\varepsilon_{p r}$ визначає стрибок функції $\varepsilon_{p}(z)$ в кінці ділянки неоднорідності. 
Точність обчислень залежить від різницевої апроксимації інтегралів у рівняннях (18-25) і від того, наскільки справедливим є наближення (28).

Точність контролювалася за допомогою рівності:

$$
\eta_{0}^{+}+\eta_{0}^{-}+\eta^{+}+\eta^{-}=1 .
$$

Чисельне розв'язування рівнянь (18-25) показало, що заміна (28) справедлива не завжди. При малих значеннях параметрів $\varepsilon$ ' та умови $\varepsilon_{p r}-1<<1$ внесок інтеграла по контуру $C_{2}$ значний і його треба враховувати. Ми обмежилися параметрами, коли можна користуватися заміною (28).

Деякі різновиди планарних плазмових антен досліджені в роботах [13-15].

\section{Розділ 2. Планарна плазмово-діелектрична антена 3 повітряним зазором}

У цьому розділі досліджується випромінювання планарної структури, яка зображена на рис. 3.

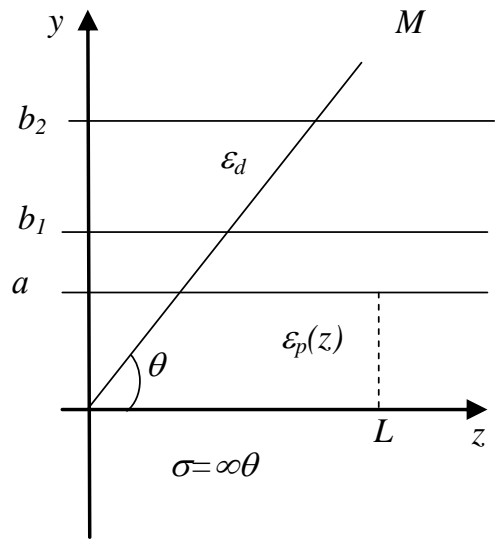

Рис. 3. Плазмовий шар товщиною $a$. Джерело: розроблено авторами.

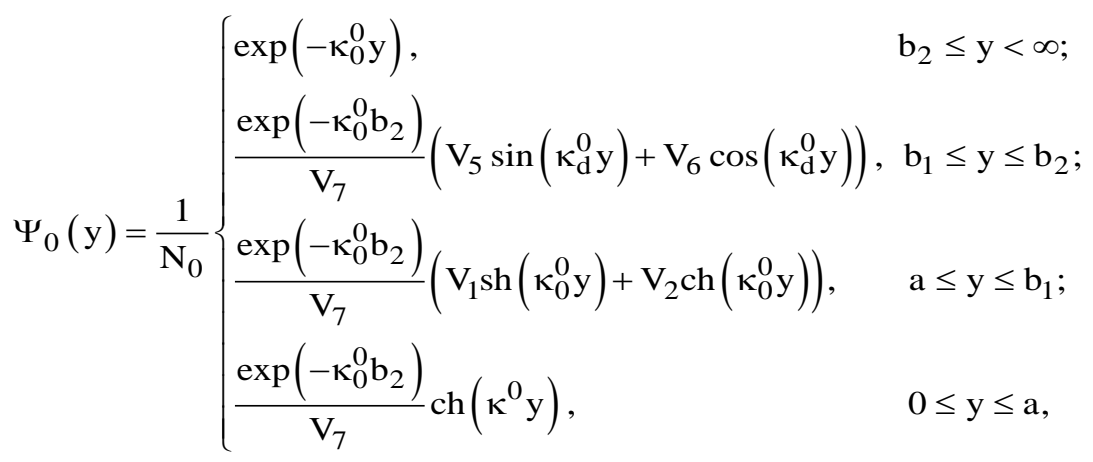

де $\left(\kappa_{0}^{0}\right)^{2}=\left(k_{z}^{0}\right)^{2}-k^{2}>0, k^{2}=\omega^{2} / c^{2}$,

$$
\begin{aligned}
& \left(\kappa^{0}\right)^{2}=\omega_{p}^{2} / c^{2}+\left(\kappa_{0}^{0}\right)^{2}>0, \\
& \left(\kappa_{d}^{0}\right)^{2}=k^{2} \varepsilon_{d}-\left(\kappa_{0}^{0}\right)^{2}>0,
\end{aligned}
$$

$N_{0}$ - нормувальний множник, який знаходиться 3 (6) (для стислості не наводиться); $V_{7}=V_{5} \sin \left(\kappa_{d}^{0} b_{2}\right)+V_{6} \cos \left(\kappa_{d}^{0} b_{2}\right)$,
На ділянці $0 \leq z \leq L$ густина плазми $n_{e}(z)$ зменшується, а іiі діелектрична проникність $\varepsilon_{p}(z)$ зростає. Товщина діелектрика дорівнює $b_{2}-b_{1}$.

При $a<y<b_{1}$ розташовано повітряний зазор. Кут між площиною $y=0$ та напрямком на точку спостереження дорівнює $\theta$.

При $y<0$ знаходиться ідеальний провідник. Спочатку розглянемо шар з однорідною густиною $n_{e}$ i, відповідно, $з$ однорідною діелектричною проникністю $\varepsilon_{p}$.

Скрізь нижче вважаємо, що $k<k_{z}^{0}<k \sqrt{\varepsilon_{d}}$. Функція $\Psi_{0}(y)$ з (3) повинна задовольняти граничним умовам на межах плазми та діелектрика:

$$
\begin{gathered}
\left.\frac{d \Psi_{0}}{d y}\right|_{y=0}=0 ; \\
\left.\Psi_{0}\right|_{y=a-0}=\left.\Psi_{0}\right|_{y=a+0} ; \\
\left.\frac{d \Psi_{0}}{d y}\right|_{y=a-0}=\left.\frac{d \Psi_{0}}{d y}\right|_{y=a+0} ; \\
\left.\Psi_{0}\right|_{y=b_{i}-0}=\left.\Psi_{0}\right|_{y=b_{s}+0} ; \\
\left.\frac{d \Psi_{0}}{d y}\right|_{y=b s-0}=\left.\frac{d \Psi_{0}}{d y}\right|_{y=b s+0} ; \\
i=1,2 .
\end{gathered}
$$

Також функція $\Psi_{0}(y)$ повинна спадати на нескінченності: $\left.\Psi_{0}\right|_{y \rightarrow \infty}=0$. В остаточному вигляді отримуємо такий вираз для $\Psi_{0}(y)$ :
$V_{5}=V_{3} \sin \left(\kappa_{d}^{0} b_{1}\right)+V_{4} \cos \left(\kappa_{d}^{0} b_{1}\right)$, $V_{6}=V_{3} \cos \left(\kappa_{d}^{0} b_{1}\right)-V_{4} \sin \left(\kappa_{d}^{0} b_{1}\right)$, $V_{4}=\frac{\kappa_{0}^{0} \varepsilon_{d}}{\kappa_{d}^{0}}\left(V_{1} \operatorname{ch}\left(\kappa_{0}^{0} b_{1}\right)+V_{2} \operatorname{sh}\left(\kappa_{0}^{0} b_{1}\right)\right)$, $V_{3}=V_{1} \operatorname{sh}\left(\kappa_{0}^{0} b_{1}\right)+V_{2} \operatorname{ch}\left(\kappa_{0}^{0} b_{1}\right)$, 


$$
\begin{aligned}
& V_{2}=\operatorname{ch}\left(\kappa_{0}^{0} a\right) \operatorname{ch}\left(\kappa^{0} a\right)-\frac{\kappa^{0}}{\kappa_{0}^{0} \varepsilon_{p}} \operatorname{sh}\left(\kappa_{0}^{0} a\right) \operatorname{sh}\left(\kappa^{0} a\right), \\
& V_{1}=\frac{\kappa^{0}}{\kappa_{0}^{0} \varepsilon_{p}} \operatorname{sh}\left(\kappa^{0} a\right) \operatorname{ch}\left(\kappa_{0}^{0} a\right)-\operatorname{ch}\left(\kappa^{0} a\right) \operatorname{sh}\left(\kappa_{0}^{0} a\right) .
\end{aligned}
$$

3 формули (33) та граничних умов (32) отримуємо дисперсійне рівняння (34). Розв'язком рівняння (34) є функція $\kappa_{z}^{0}=\kappa_{z}^{0}(\omega)$, яка необхідна для входження в рівняння (18-25). Для просторових хвиль, що існують за умови $\kappa_{0}^{2}=k^{2}-k_{z}^{2}>0$, функція $\Psi\left(y, \kappa_{0}\right) \equiv H_{x}\left(y, \kappa_{0}\right)$ з (5) також повинна задоволь-

$$
\begin{aligned}
& W_{8}=W_{5} \cos \left(\kappa_{d} b_{2}\right)-W_{6} \sin \left(\kappa_{d} b_{2}\right), \\
& W_{7}=W_{5} \sin \left(\kappa_{d} b_{2}\right)+W_{6} \cos \left(\kappa_{d} b_{2}\right), \\
& W_{6}=W_{3} \cos \left(\kappa_{d} b_{1}\right)-W_{4} \sin \left(\kappa_{d} b_{1}\right), \\
& W_{5}=W_{3} \sin \left(\kappa_{d} b_{1}\right)+W_{4} \cos \left(\kappa_{d} b_{1}\right), \\
& W_{4}=-\frac{\kappa_{0} \varepsilon_{d}}{\kappa_{d}}\left(W_{1} \sin \left(\kappa_{0} b_{1}\right)-W_{2} \cos \left(\kappa_{0} b_{1}\right)\right), \\
& W_{3}=W_{1} \cos \left(\kappa_{0} b_{1}\right)+W_{2} \sin \left(\kappa_{0} b_{1}\right), \\
& W_{2}=\frac{\kappa}{\kappa_{0} \varepsilon_{p}} \operatorname{sh}(\kappa a) \cos \left(\kappa_{0} a\right)+\sin \left(\kappa_{0} a\right) \operatorname{ch}(\kappa a), \\
& W_{1}=\operatorname{ch}(\kappa a) \cos \left(\kappa_{0} a\right)-\frac{\kappa}{\kappa_{0} \varepsilon_{p}} \sin \left(\kappa_{0} a\right) \operatorname{sh}(\kappa a) .
\end{aligned}
$$

За допомогою співвідношень $(3,5,15,16)$ знаходимо функції $J_{0}(z), \quad J_{1}\left(\tilde{\kappa}_{0}, z\right)$, $J_{2}\left(\kappa_{0}, z\right), J_{3}\left(\kappa_{0}, \tilde{\kappa}_{0}, z\right)$, які входять до рівняння (18-25) (відповідні формули для стислості не наводяться).

Наведемо деякі приклади обчислення коефіцієнта перетворення енергії поверхневої хвилі $\eta^{+}\left(\varepsilon^{\prime}\right)$. На рис. 4-7 представлені результати обчислення цієї величини при різних параметрах хвилепровідної системи, зображеної на рис. 3, в залежності від градієнту діелектричної проникності плазми $\varepsilon^{\prime}$.

$$
\begin{aligned}
& \left\{1+\frac{\kappa^{0}}{\kappa_{0}^{0} \varepsilon_{p}} \operatorname{th}\left(\kappa^{0} a\right) \operatorname{th}\left(\kappa_{0}^{0}\left(b_{1}-a\right)\right)\right\} \\
& \left\{\operatorname{cth}\left(\kappa_{d}^{0}\left(b_{2}-b_{1}\right)\right)-\frac{\kappa_{d}^{0}}{\kappa_{0}^{0} \varepsilon_{d}}\right\}+ \\
& +\frac{\kappa_{0}^{0} \varepsilon_{d}}{\kappa_{d}^{0}}\left\{\frac{\kappa^{0}}{\kappa_{0}^{0} \varepsilon_{p}} \operatorname{th}\left(\kappa^{0} a\right)+\operatorname{th}\left(\kappa_{0}^{0}\left(b_{1}-a\right)\right)\right\} \\
& \left\{1+\frac{\kappa_{d}^{0}}{\kappa_{0}^{0} \varepsilon_{d}} \operatorname{cth}\left(\kappa_{d}^{0}\left(b_{2}-b_{1}\right)\right)+1\right\}=0 .
\end{aligned}
$$
няти граничним умовам (32).

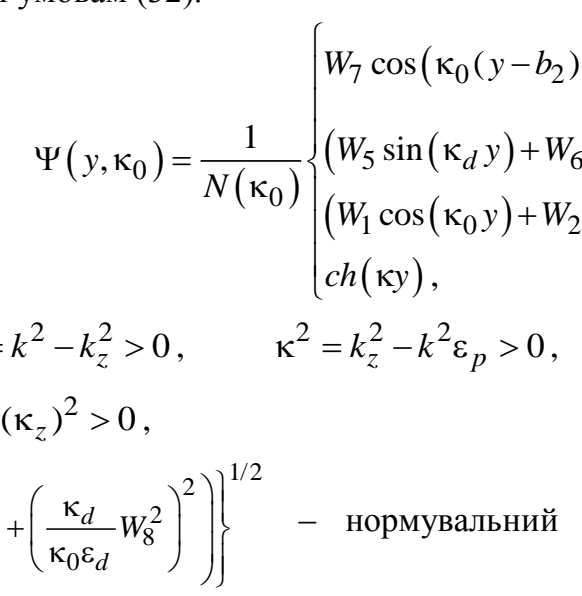

множник, який знаходиться 3 умови (6),

В результаті отримуємо формулу:

де $\quad\left(\kappa_{0}\right)^{2}=k^{2}-k_{z}^{2}>0, \quad \kappa^{2}=k_{z}^{2}-k^{2} \varepsilon_{p}>0$,

$\left(\kappa_{d}\right)^{2}=k^{2} \varepsilon_{d}-\left(\kappa_{z}\right)^{2}>0$

$N\left(\kappa_{0}\right)=\left\{\frac{\pi}{2}\left(W_{7}^{2}+\left(\frac{\kappa_{d}}{\kappa_{0} \varepsilon_{d}} W_{8}^{2}\right)^{2}\right)\right\}^{1 / 2}-$ нормувальний$$
\text { - }
$$ 
поверхневої хвилі перетворюється у головну енергію випромінювання під гострими кутами та енергію, яка пройшла через неоднорідність поверхневої хвилі.

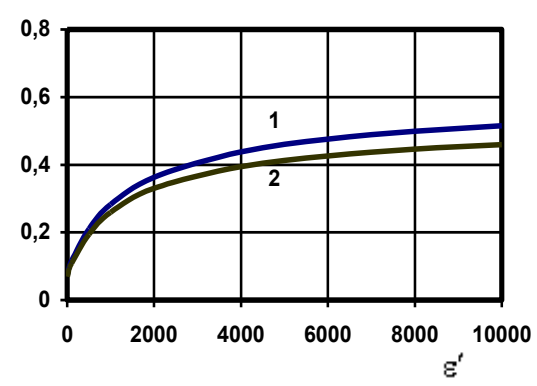

Рис. 6. Залежність $\eta^{+}$від $\varepsilon^{\prime}$; при $L / \lambda=0,1 ; a / \lambda=$ $0.01 ; b_{2} / b_{1}=1.2 ;$ лінія 1 відповідає $-b_{1} / a=1.1$, лінія $2-b_{1} / a=1,5$, в обох випадках $\varepsilon_{p r}=1, \varepsilon_{d}=10$.

Джерело: розроблено авторами.

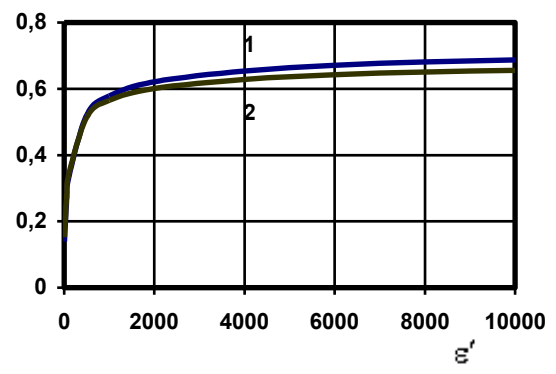

Рис. 7. Залежність $\eta^{+}$від $\varepsilon^{\prime}$; при $L / \lambda=0,1$; $a / \lambda=0.03 ; b_{2} / b_{1}=1.2$; лінія 1 відповідає $-b_{1} / a=$ 1.1 , лінія $2-b_{1} / a=1,5$, в обох випадках $\varepsilon_{p r}=1, \varepsilon_{d}=10$. Джерело: розроблено авторами.

Частка енергії відбитої поверхневої і розсіяної назад хвиль дуже мала. Тому коефіцієнти $\eta_{0}^{-}, \eta^{-}$на порядок менше, ніж $\eta^{+}$, вони не наведені у статті. Коефіцієнт $\eta^{+}$зростає з ростом градієнта діелектричної проникності $\varepsilon$ й досягає значень $\eta^{+} \approx 50-$ $70 \%$ в залежності від геометричних параметрів та фізичних властивостей антени. Функція $\eta^{+}\left(\varepsilon^{\prime}\right)$, монотонно зростає, тому при $\varepsilon '>10000$ можливо випромінювання 3 ще більшою ефективністю. 3 ростом $\varepsilon^{\prime}$, проте, треба зменшувати кроки інтегрування в (18-25). Це, в свою чергу, вимагає непомірно великих комп'ютерних ресурсів.

Прийнятним максимальним значенням градієнта щільності можна вважати $\varepsilon^{\prime}=10000$. Додатковий аналіз показав, що при збільшенні відносної товщини стінки діелектрика $b_{2} / b_{1}$ коефіцієнт $\eta^{+}$зменшується. Фізично це пояснюється наступним чином. Поверхнева хвиля частково поширюється по діелектрику. Ця частина хвилі поширюється, не спотворюючи, оскільки діелектрик однорідний. Трансформація хвилі відбувається тільки на неоднорідностях плазми. Поздовжньо однорідні відкриті хвилеведучі системи не випромінюють. Це можна уявити собі по аналогії з поширенням хвилі у однорідному середовищі. В цьому випадку хвиля поширюється, не спотворюючись (не розсіюючись).

Неоднорідність плазми є тим об'єктом, на якому хвиля розсіюється (дифрагують). Хвиля, що розсіює $є$ хвилею випромінювання. Найпростіший приклад - нескінченно довга прямолінійна поздовжньо однорідна антена не випромінює. Фізично це пояснюється тим, що поля в точці спостереження, створювані окремими ділянками такої антени, інтерферуючи, компенсуються. Звичайно, мова йде про випромінювання в дальній зоні. Отже, чим товще діелектрик, тим в середньому більша однорідна плазмова антена, що призводить до послаблення трансформації поверхневої хвилі у випромінювання.

Аналіз показав також, що функція $\eta^{+}\left(\varepsilon^{\prime}\right)$ слабо змінюється при зміні електричної довжини ділянки неоднорідності $L / \lambda$ і визначається електричної товщиною плазмового шару та діелектрика. 3 ростом стрибка діелектричної проникності плазми в кінці ділянки неоднорідності, що визначається параметром $\varepsilon_{p r}$, ефективність перетворення енергії поверхневої хвилі в випромінювання, тобто параметр $\eta^{+}$, при інших рівних умовах зменшується.

Тому, для ефективної роботи антени щільність плазми в кінці ділянки неоднорідності плазми повинна бути, наскільки це можливо, малою в порівнянні 3 щільністю на початку ділянки неоднорідності.

Приклади нормованих діаграм спрямованості (НДС) наведені на рис. 8 для різних діелектриків.

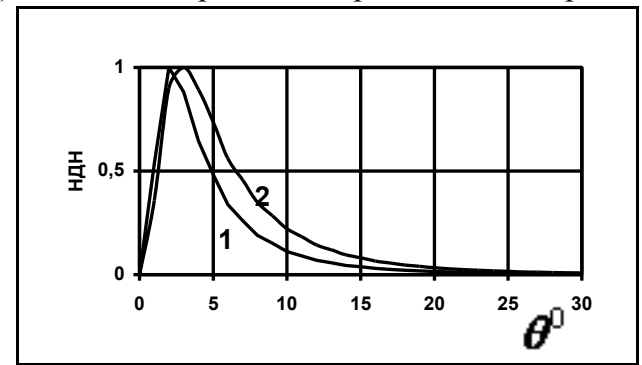

Рис. 8. НДС для різних значень $\varepsilon_{d} . L / \lambda=0.1$,

$$
\begin{gathered}
a / \lambda=0.03, b_{2} / b_{1}=1.2, b_{1} / a=1.1, \varepsilon_{p r}=1, \\
\varepsilon^{\prime}=10000 \text {. Лінія } 1-\text { відповідає. } \varepsilon_{d}=2.5, \\
\text { лінія } 2-\varepsilon_{d}=10 .
\end{gathered}
$$

Джерело: розроблено авторами. 
Відзначимо дві важливі позитивні особливості НДС, характерні для хвилеводу, показаного на рис. 3.

По-перше, у НДС відсутні бічні пелюстки. Подруге, НДС є гостроспрямованою 3 максимумом, розташованим під малими кутами $\theta_{m}$ до осі $z$. Ширини НДС на половині висоті не перевищують $5^{\circ}$.

При збільшенні діелектричної проникності $\varepsilon_{d}$ збільшується уповільнення поверхневої хвилі за рахунок діелектричної оболонки. 3 ростом уповільнення кут максимального випромінювання збільшується і наближається до значення $\pi / 2$. Це є загальною властивістю антен біжучої хвилі [16]. Тому $\theta_{m}$ для НДС збільшується зі зростанням величин $\varepsilon_{d}$.

\section{Розділ 3. Планарна плазмова антена 3 двостороннім діелектричним покриттям}

Розглянемо випромінювання планарної плазмово-діелектричної структури, зображеної на рис. 9. У такому відкритому хвилеводі існують парні та непарні хвилі по координаті $y$.

Тут досліджується парна хвиля.

В силу симетрії плазмово-діелектричної хвилеводу, показаного на рис. 9, випромінювання симетрично відносно площини $y=0$.

Функція $\Psi_{0}^{p}(y)$ з (3), яка визначає магнітне поле парної хвилі повинна задовольняти граничним умовам аналогічним (32) і спадати на нескінченності $\left.\Psi_{0}^{p}\right|_{y \rightarrow \infty}=0$. Ця функція визначається виразом.

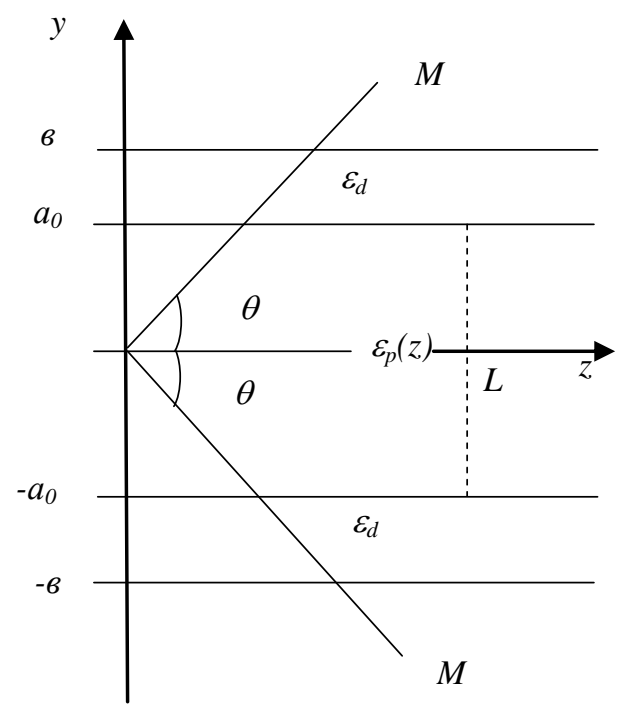

Рис. 9. Плазмовий шар товщиною $2 a_{0}$. Джерело: розроблено авторами.
На ділянці $0 \leq z \leq L$ густина плазми $n_{e}(z)$ зменшується, а іiі діелектрична проникність $\varepsilon_{p}(z)$ зростає.

Товщина діелектричних шарів дорівнює $b-a_{0}$. Кут між площиною $y=0$ та напрямком на точку спостереження дорівнює $\theta$.

$$
\begin{gathered}
\Psi_{0}^{p}(y)= \\
\frac{1}{N_{0}^{p}}\left\{\begin{array}{l}
\exp \left(\kappa_{0}^{0} b\right) \\
\tilde{V}_{1} \exp \left(-\kappa_{0}^{0} y\right), b \leq y<\infty, \\
\left(\tilde{V}_{2} \sin \left(\kappa_{d}^{0} y\right)-\tilde{V}_{3} \cos \left(\kappa_{d}^{0} y\right)\right),-a_{0} \leq y \leq a_{0},-a_{0} \leq y \leq a_{0}, \\
-\tilde{V}_{2} \sin \left(\kappa_{d}^{0} y\right)-\tilde{V}_{3} \cos \left(\kappa_{d}^{0} y\right),-b \leq y \leq-a_{0}, \\
\frac{\exp \left(\kappa_{0}^{0} b\right)}{\tilde{V}_{1}} \exp \left(\kappa_{0}^{0} y\right),-\infty \leq y \leq-b,
\end{array}\right.
\end{gathered}
$$

де $\kappa_{0}^{0}, k^{2}, \kappa^{0}, \kappa_{d}^{0}$ визначені вище,

$N_{0}^{p}$ - нормувальний множник, який знаходиться з умови (4) (для стислості не наводиться);

$$
\begin{aligned}
& \tilde{V}_{1}=\left(\operatorname{ch}\left(\kappa^{0} a_{0}\right)+\frac{\varepsilon_{p} \kappa_{0}^{0}}{\kappa^{0}} \operatorname{sh}\left(\kappa^{0} a_{0}\right)\right) \cos \left(\kappa_{d}^{0}\left(b-a_{0}\right)\right)+ \\
& +\left(\frac{\kappa_{0}^{0} \varepsilon_{d}}{\kappa_{d}^{0}} \operatorname{ch}\left(\kappa^{0} a_{0}\right)-\frac{\varepsilon_{p} \kappa_{d}^{0}}{\kappa^{0} \varepsilon_{d}} \operatorname{sh}\left(\kappa^{0} a_{0}\right)\right) \sin \left(\kappa_{d}^{0}\left(b-a_{0}\right)\right) ; \\
& \tilde{V}_{2}=\frac{\kappa^{0} \varepsilon_{d}}{\varepsilon_{p} \kappa_{d}^{0}} \operatorname{sh}\left(\kappa^{0} a_{0}\right) \cos \left(\kappa_{d}^{0} a_{0}\right)+\operatorname{ch}\left(\kappa^{0} a_{0}\right) \sin \left(\kappa_{d}^{0} a_{0}\right) ; \\
& \tilde{V}_{3}=\frac{\kappa^{0} \varepsilon_{d}}{\varepsilon_{p} \kappa_{d}^{0}} \operatorname{sh}\left(\kappa^{0} a_{0}\right) \sin \left(\kappa_{d}^{0} a_{0}\right)-\operatorname{ch}\left(\kappa^{0} a_{0}\right) \cos \left(\kappa_{d}^{0} a_{0}\right) .
\end{aligned}
$$

Дисперсійне рівняння, яке відповідає хвилі (36) має вигляд:

$$
\begin{gathered}
\operatorname{th}\left(\kappa^{0} a_{0}\right)+\frac{\varepsilon_{p} \kappa_{0}^{0}}{\kappa^{0}}+\operatorname{tg}\left(\kappa_{d}^{0}\left(b-a_{0}\right)\right) \times \\
\times\left\{\frac{\kappa_{0}^{0} \varepsilon_{d}}{\kappa_{d}^{0}} \operatorname{th}\left(\kappa^{0} a_{0}\right)-\frac{\varepsilon_{p} \kappa_{d}^{0}}{\kappa^{0} \varepsilon_{d}}\right\}=0 .
\end{gathered}
$$

Розв’язком рівняння (37) є дисперсійна функція $\kappa_{z}^{0}=\kappa_{z}^{0}(\omega)$.

Для просторових хвиль, що існують за умови $\kappa_{0}^{2}=k^{2}-k_{z}^{2}>0$, функція $\Psi\left(y, \kappa_{0}\right) \equiv H_{x}\left(y, \kappa_{0}\right)$ з (5) визначається виразом: 


$$
\Psi^{p}\left(y, \kappa_{0}\right)=\frac{1}{N^{p}\left(\kappa_{0}\right)}\left\{\begin{array}{l}
\tilde{W}_{1} \cos \left(\kappa_{0}(y-b)\right)+\frac{\kappa_{d}}{\kappa_{0} \varepsilon_{d}} \tilde{W}_{2} \sin \left(\kappa_{0}(y-b)\right), b \leq y<\infty, \\
\left(\tilde{W}_{3} \sin \left(\kappa_{d} y\right)+\tilde{W}_{4} \cos \left(\kappa_{d} y\right)\right), a_{0} \leq y \leq b ; \\
c h(\kappa y),-a_{0} \leq y \leq a_{0},-a_{0} \leq y \leq a_{0},-a_{0} \leq y \leq a_{0} ; \\
\left(-\tilde{W}_{3} \sin \left(\kappa_{d} y\right)+\tilde{W}_{4} \cos \left(\kappa_{d} y\right)\right),-b \leq y \leq-a_{0} ; \\
\tilde{W}_{1} \cos \left(\kappa_{0}(y+b)\right)-\frac{\kappa_{d}}{\varepsilon_{d} \kappa_{0}} \tilde{W}_{2} \sin \left(\kappa_{0}(y+b)\right),-\infty<y \leq-b,
\end{array}\right.
$$

де $\kappa^{0}, k, \kappa^{0}, \kappa_{d}-$ визначені вище,

$N^{p}\left(\kappa_{0}\right)=\left\{\pi\left(\tilde{W}_{1}^{2}+\left(\frac{\kappa_{d}}{\kappa_{0} \varepsilon_{d}} \tilde{W}_{2}\right)^{2}\right)\right\}^{1 / 2}-$ нормуваль-

ний множник, який знаходиться з умови (4).

$\tilde{W}_{1}=\tilde{W}_{3} \sin \left(\kappa_{d} b\right)+\tilde{W}_{4} \cos \left(\kappa_{d} b\right)$,

$\tilde{W}_{2}=\tilde{W}_{3} \cos \left(\kappa_{d} b\right)-\tilde{W}_{4} \sin \left(\kappa_{d} b\right)$,

$\tilde{W}_{3}=\frac{\kappa \varepsilon_{d}}{\kappa_{p} \varepsilon_{p}} \operatorname{sh}\left(\kappa a_{0}\right) \cos \left(\kappa a_{0}\right) \cos \left(\kappa_{d} a_{0}\right)+\operatorname{ch}\left(\kappa a_{0}\right) \times$

$\times \sin \left(\kappa_{d} a_{0}\right)$,

$\tilde{W}_{4}=\cos \left(\kappa_{d} a_{0}\right) \operatorname{ch}\left(\kappa a_{0}\right)-\frac{\kappa \varepsilon_{d}}{\kappa_{d} \varepsilon_{p}} \operatorname{sh}\left(\kappa a_{0}\right) \sin \left(\kappa_{d} a_{0}\right)$.

Зі співвідношень $(3,5,15,16)$ отримуємо функції $J_{0}(z), J_{1}\left(\tilde{\kappa}_{0}, z\right), J_{2}\left(\kappa_{0}, z\right), J_{3}\left(\kappa_{0}, \tilde{\kappa}_{0}, z\right)$.

На рис.10, 11 представлені результати обчислення коефіцієнта $\eta^{+}\left(\varepsilon^{\prime}\right)$ в залежності від градієнта діелектричної проникності. Параметри хвилеводу вказані у підписах до рисунків.

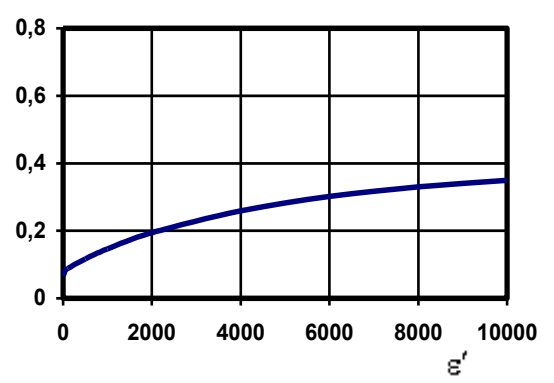

Рис. 10. Залежність $\eta^{+}$від $\varepsilon^{\prime}$; при $L / \lambda=0,1$; $\left(b-a_{0}\right) / 2 a_{0}=0.2 ; 2 a_{0} / \lambda=0.01, \varepsilon_{p r}=1, \varepsilon_{d}=2.5$.

Джерело: розроблено авторами.

Властивості залежностей $\eta^{+}\left(\varepsilon^{\prime}\right)$ в даному випадку багато в чому схожі з аналогічними залежностями для відкритого хвилеводу, показаного на рис. 3 . Видно, що вдається обчислити коефіцієнт $\eta^{+} 3$ достатньою точністю при дуже швидкій зміні густини плазми. Енергія поверхневої хвилі перетворюється в основному в енергію випромінювання під гострими кутами. Коефіцієнти $\eta_{0}^{-}, \eta^{-}$менші, ніж $\eta^{+}$.

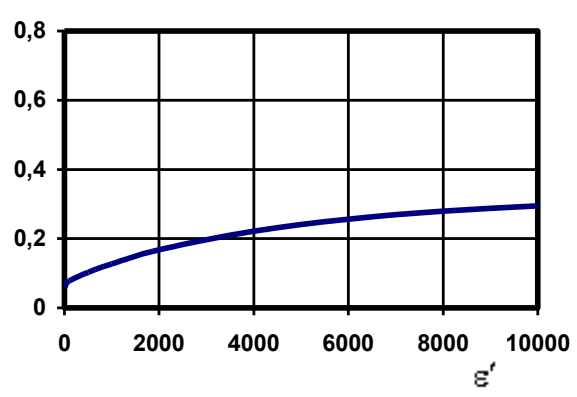

Рис. 11. Залежність $\eta^{+}$від $\varepsilon^{\prime}$; при $L / \lambda=0,1$; $\left(b-a_{0}\right) / 2 a_{0}=0.2 ; 2 a_{0} / \lambda=0.01, \varepsilon_{p r}=1, \varepsilon_{d}=10$.

Джерело: розроблено авторами.

Коефіцієнт $\eta^{+}$зростає 3 ростом градієнта діелектричної проникності $\varepsilon$ ' $\eta^{+} \approx 30-35 \%$ в залежності від геометричних параметрів антени та вибору діелектрика. Для ефективної роботи антени густина плазми в кінці ділянки неоднорідності плазми повинна бути, наскільки це можливо, малою в порівнянні 3 щільністю на початку ділянки неоднорідності. Приклади нормованих діаграм спрямованості (НДС) наведені на рис. 12.

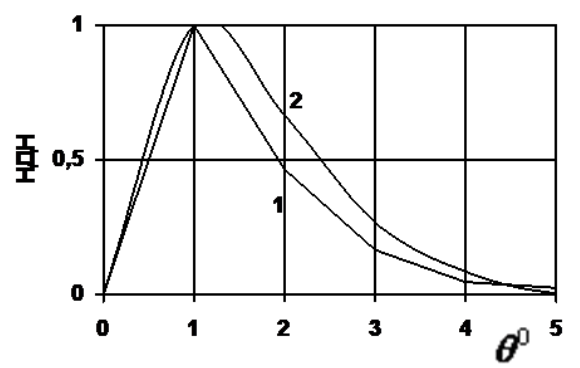

Рис. 12. НДС для різних значень $\varepsilon_{d} . L / \lambda=0.1$,

$a / \lambda=0.01,\left(b-a_{0}\right) / 2 a_{0}=0.2, \varepsilon_{p r}=1, \varepsilon^{\prime}=10000$.

Лінія 1 - відповідає. $\varepsilon_{d}=2.5$, лінія $2-\varepsilon_{d}=10$.

Джерело: розроблено авторами.

Відзначимо дві важливі позитивні особливості НДС, характерних для хвилеводу, показаного на рис. 9. По-перше, у НДС відсутні бічні пелюстки. По-друге, НДС є гостроспрямованою з максимумом, розташованим під малими кутами $\theta_{m}$ до осі $z$. Ширини НДС на половині висоти дуже малі і складають 1.5-2 ${ }^{0}$. 


\section{Висновок}

Таким чином розглянуті в даній роботі планарні плазмові антени з сильною поздовжньою неоднорідністю $є$ основою для створення антен з гостронаправленим при осьовим випромінюванням. У такій плазмовій антені енергія, що вводиться в антену, з високою ефективністю перетворюється у випромінювання під гострими кутами. Крім того, позитивною властивістю таких антен є відсутність бічних пелюсток у діаграмі спрямованості.

Отримані в даній роботі результати можуть бути використані при розробці малопомітних плазмових антен біжучої хвилі.

\section{Список літератури}

1. Borg G. G., Harris J. H., Martin N. M. Plasmas as antennas : Theory, experiment and applications. Physics of Plasmas. 2000. № 7(5). P. 2198-2202. https://doi:10.1063/1.874041.

2. Rayner J. P., Whichello A. P. Physical characteristics of plasma antennas. IEEE Transaction on plasma science. 2004. № 32. Р. 269-281.

3. Минаев И. М., Рухадзе А. А., Сергейчев К. Ф. и др. Активная плазменная ВЧ-антенна, самосогласованная с источником колебаний. Краткие сообщения по физике. 2005. № 12. С. 34-44.

4. Istomin E. N., Carfidov D. M., Minaev I. M. Plasma unbalanced vibrator with surfaces wave excitation. Plasma physics. 2006. № 5(32). P.423-435.

5. Гусейн-заде Н. Г., Минаев И. М., Рухадзе А. А. Физические принципы работы плазменных антенн. Радиотехника и электроника. 2011. № 10(56). С. 1216-1220.

6. Tuma D. R. A quiet uniform microwave gas discharge for lasers. Review of Scientific Instruments. 1970. Vol. 41. P. 1519-1520.

7. Moisan M., Beaudry C., Leprince P. A new HF device for the production of long plasma columns at high electron density. Physics Letters. 1974. Vol. 5. P.125-126.

8. Azarenkov N. A., Denisenko I. V., Ostrikov K. N. A model of a large-area planar plasma produced based on surface wave propagation in a plasma-metal structure with a dielectric sheath. Journal of Physics D. 1995. Vol. 28. P. 2465-2469.

9. Кузелев М. В., Рухадзе А. А., Стрелков П. С. Плазменная релятивистская СВЧ- електроніка. Москва : Изд-во МГТУ им. Баумана, 2002. 544 с.

10. Артеменко А. Н., Карлов В. Д., Кириченко Ю. В. Теоретические основы плазменных антенн бегущей волны. Харьков : ХНУПС, 2018. $194 \mathrm{c}$.

11. Шевченко В. В. Плавные переходы в открытых волноводах. Введение в теорию. Москва : Наука, 1969. 192 с.

12. Ириков В. А., Нефедов Е. И., Шевченко В. В. Численное решение задачи об излучении поверхностной волны неоднородным участком. Радиоэлектроника. 1968. № 5(13). С. 923.

13. Кириченко Ю. В. Излучение продольно неоднородного плазменного слоя. Радиотехника и электроника. 2017. № 2(62). C. 165-174.

14. Kirichenko Yu. V. Radiation from a plasma layer with a strong longitudinal irregularity. Journal of communications technology and electronics. 2017. № 12(62). P. 1215-1223.

15. Артеменко А. М., Карлов В. Д., Кириченко Ю. В., Лонін Ю. Ф. Планарна плазмова антена з діелектричним покриттям. Радіофізика та електроніка. 2020. № 1(25). С. 50-59. https://doi.org/10.15407/rej2020.01.050.

16. Walter C. H. Traveling wave antennas. New York: McGraw-Hill Book, 1965. 429 p.

\section{Відомості про авторів:}

\section{Кириченко Юрій Васильович}

доктор фізико-математичних наук

старший науковий співробітник

Національний науковий центр

Харківського фізико-технічного інституту,

Харків, Україна

https://orcid.org/0000-0002-8723-6192

\section{Лонін Юрій Федорович}

доктор технічних наук старший науковий співробітник

Національний науковий центр

Харківський фізико-технічний інститут,

Харків, Україна

https://orcid.org/0000-0002-4833-091X

\section{Струцінський Олег Васильович}

кандидат технічних наук

Командувач підготовки Командування

Повітряних Сил Збройних Сил України,

Вінниця, Україна

https://orcid.org/0000-0002-6175-7678

\section{Information about the authors:}

Yuri Kirichenko

Doctor of Physical and Mathematical Sciences

Senior Research

National Science Center Kharkov Institute

of Physics and Technology,

Kharkiv, Ukraine

https://orcid.org/0000-0002-8723-6192

\section{Yuri Lonin}

Doctor of Technical Sciences Senior Research

National Science Center Kharkov Institute

of Physics and Technology,

Kharkiv, Ukraine

https://orcid.org/0000-0002-4833-091X

\section{Oleh Strutsinskiy}

Candidate of Technical Sciences

Training Commander of the Air Force Command

of the Armed Force of Ukraine,

Vinnytsia, Ukraine

https://orcid.org/0000-0002-6175-7678 
Кузнсцов Олександр Леонідович

кандидат технічних наук доцент

професор кафедри

Харківського національного університету

Повітряних Сил ім. І. Кожедуба,

Харків, Україна

https://orcid.org/0000-0002-5915-8107

Бссова Оксана Василівна

кандидат технічних наук старший науковий співробітник

Харківського національного університету

Повітряних Сил ім. I Кожедуба,

Харків, Україна

https://orcid.org/0000-0001-7744-1339

Лукашук Олена В'ячеславівна

кандидат технічних наук

доцент кафедри Харківського національного

університету Повітряних Сил ім. І. Кожедуба,

Харків, Україна

https://orcid.org/0000-0001-8721-2433
Oleksandr Kuznietsov

Candidate of Technical Sciences

Associate Professor

Professor of Ivan Kozhedub

Kharkiv National Air Force University,

Kharkiv, Ukraine

https://orcid.org/0000-0002-5915-8107

\section{Oksana Biesova}

Candidate of Technical Sciences

of Ivan Kozhedub

Kharkiv National Air Force University,

Kharkiv, Ukraine

https://orcid.org/0000-0001-7744-1339

Olena Lukashuk

Candidate of Technical Sciences

Senior Lecturer of Ivan Kozhedub

Kharkiv National Air Force University,

Kharkiv, Ukraine

https://orcid.org/0000-0001-8721-2433

\section{ПЛАНАРНЫЕ АНТЕННЫ НА ОСНОВЕ ПРОДОЛЬНО НЕОДНОРОДНЫХ ПЛАЗМЕННЫХ СЛОЕВ}

Ю.В. Кириченко, Ю.Ф. Лонин, О. В. Струцинский, А.Л. Кузнецов, О.В. Бесова, Е.В. Лукашук

Эффективным способом снижения радиолокационной заметности летательных аппаратов есть применение плазменных антенн. Для них эффективная поверхность рассеяния электромагнитных волн на несколько порядков меньше, чем для металлических антенн. В работе исследованы две модели планарной плазменной антенны. $B$ первой модели покрытый диэлектриком продольно неоднородный слой плазмы находится на металлической поверхности. Во второй модели такой же плазменный слой распложен между двумя диэлектриками. В обоих случаях плазма является электронной холодной и изотропной. Продольная неоднородность учитывается методом спектрального разложения электромагнитного поля по набору поверхностных и пространственных волн. Вычислены нормированные диаграммы направленности (НДН) и коэффициенты преобразования энергии поверхностных волн в энергию излучения. Показано, что НДН имеют один лепесток, максимумом которого расположен под острым углом к плоскости антенны. Ширина лепестков составляет несколько градусов.

Ключевые слова: плазменные антенны, неоднородная плазма, метод спектрального разложения, диаграмма направленности излучения, открытые волноводы.

\section{PLANAR ANTENNAS BASED ON LONGITUDINALLY INHOMOGENEOUS PLASMA LAYERS}

Yu. Kirichenko, Yu. Lonin, O. Strutsinskiy, O. Kuznietsov, O. Biesova, O. Lukashuk

Reducing the effective scattering surface of antenna systems without significantly deteriorating their characteristics is an urgent task from both technical and tactical points of view. Traditional antenna masking methods cannot be used without degrading their technical characteristics. A promising direction for creating inconspicuous antennas is the use of low-temperature plasma in them. Therefore, an effective way to solve this problem is to use plasma antennas, for which the effective scattering surface of electromagnetic waves is several orders of magnitude smaller than for metal antennas. This work investigates the transformation of surface waves into radiation in a plane limited plasma layer of finite thickness, which rapidly changes in the longitudinal direction. Two models of a planar plasma antenna are considered. In the first model, a longitudinally inhomogeneous plasma layer covered with a dielectric is located on a metal surface. In the second model, the same plasma layer is located between two dielectrics. In both cases, the plasma is electron cold and isotropic. Longitudinal inhomogeneity is taken into account by the method of spectral decomposition of the electromagnetic field by a set of surface and spatial waves. The normalized radiation patterns (NDP) and the conversion coefficients of the energy of surface waves into radiation energy are calculated. It is shown that NDP have one lobe, the maximum of which is located at an acute angle to the antenna plane. In this case, the width of the petals is several degrees. The results obtained can be practically used in solving the problem of increasing the survivability of modern radio engineering systems in the conditions of the possible use of high-precision weapons by the enemy.

Keywords: plasma antennas, planar plasma antenna, spectral decomposition method, radiation, surface wave, pattern. 